\title{
Trabzon Civarındaki Fay Türü Jeolojik Yapıların Gravite Verileri Kullanılarak Belirlenmesi
}

\author{
Identification of Fault Type Geological Structures around Trabzon by Using Gravity Data
}

\author{
Ali ELMAS \\ Karadeniz Teknik Üniversitesi, Mühendislik Fakültesi, Jeofizik Mühendisliği Bölümü, TRABZON
}

Geliş (Received): 2 Mayıs (May) 2017, Düzeltme (Revised): 12 Eylül (September) 2017, Kabul (Accepted): 19 Eylül (September) 2017

ÖZ

Bu çalışmanın amacı, Trabzon civarındaki fay türü jeolojik yapıların gravite verileri kullanılarak belirlenmesidir. $\mathrm{Bu}$ amaçla toplam yatay türev, analitik sinyal, eğim açısı ve hiperbolik eğim açısı teknikleri kullanılmıştır. Kullanılan bu teknikler bölgeye ait gravite verilerinin birinci düşey türev değerlerine uygulanmıştır. Bölgeye ait fay türü jeolojik yapılar belirlenirken, toplam yatay türev ve analitik sinyal haritalarının maksimum genlik değerleri ile eğim açısı ve hiperbolik eğim açısı haritalarının sıfır genlik değerlerinden yararlanılmıştır. Temel kaya topoğrafyası, ParkerOldenburg algoritması kullanılarak hesaplanmıştır. Belirlenen fay türü jeolojik yapılar, bölgedeki mevcut faylarla karşılaştırılmıştır. Bu çalışma ile önceki çalışmalar arasında iyi bir uyum olmakla birlikte, yeni fay türü jeolojik yapılar bulunmuştur. Bu fay türü jeolojik yapıların bölgedeki dağılımı ile bölgedeki maden yataklarının dağılımı ve bölgede yaşanmış depremlerin dış merkez dağılımları arasında önemli bir ilişki olduğu görülmüştür. Bu çalışmada, bölgenin jeolojik yapısının daha iyi anlaşılması için yapılacak çalışmalara ve büyük ölçekli jeolojik araştırmalara yol gösterecek şekilde sonuçlar elde edilmiştir. Ayrıca çalışmanın sonuçlarının, yeni maden yataklarının aranmasında ve deprem açısından riskli yerlerin belirlenmesinde yol gösterici olabileceği düşünülmektedir.

Anahtar Kelimeler: Analitik Sinyal, Eğim Açısı, Hiperbolik Eğim Açısı, Trabzon ve Civarı, Toplam Yatay Türev.

\begin{abstract}
The aim of this study is to define the fault related geological structures using gravity data around Trabzon. For this purpose, horizontal gradient magnitude, analytic signal, tilt angle, and hyperbolic of tilt angle techniques were operated. By applying these techniques to the first vertical derivative of the regional gravity data, faultsrelated geological structures were identified from maximum amplitude values with horizontal gradient magnitude and analytic signal maps, and zero amplitude values of the tilt angle and hyperbolic of tilt angle maps for this region. The basement topography was calculated using the Parker-Oldenburg algorithm. Identified fault-related geological structures were compared with the existing faults in the region. Although there is a good agreement between this study and the previous studies, some new fault-related structures were also identified. There is a significant relationship among the distribution of the fault-related geological structures, mineral deposits, and also earthquake epicenters in the region. This study was resulted to shed some light on the other following small to large scale geological studies
\end{abstract}


Elmas

for better understanding of the geological structure of the region. It is also believed that the results of the study may be a guide to the search for new mineral deposits and the identification of risky locations for earthquakes.

Keywords: Analytic Signal, Tilt Angle, Hyperbolic of Tilt Angle, Trabzon and Vicinity, Horizontal Gradient Derivative.

\section{GİRIŞ̧}

Önem taşıyan ve yer altında bulunan jeolojik birimlerin araştırılmasında, sahada direk gözlemin her zaman mümkün olmadığ1 durumlarda başka tekniklerden yararlanılması gerekir. Örneğin altın aramacılığında jeofizik yöntemlerden yararlanılarak altın bulunmuştur (Ercan vd., 2014).

Anadolu'nun kuzeydoğusunda, Karadeniz sahiline paralel uzanan Doğu Pontidler, çeşitli mineral sistemlerini içerir (Akaryali ve Tüysüz, 2013). Çalışma alanı, Doğu Pontidler'in kuzey zonu içerisinde kalmaktadır (Şekil 1). Uluslararası Sismoloji Merkezi (ISC) verilerine göre bölge eski çağlardan beri birçok deprem yaşamıştır. Bölgede deprem odak derinlikleri genellikle $15 \mathrm{~km}$ civarındadır, ancak az da olsa 50 km'lere kadar inmektedir (Şekil 2).

Doğu Karadeniz Dağları'nın kuzey kesimlerinin genel jeolojisine ve stratigrafisine bakıldığında, Paleozoyik'ten Pliyosen'e kadar değişik yaşta ve türde kayaçların varlığı gözlenir. Metamorfitler üzerine uyumsuzlukla gelen Mesozoyik yaşlı ilk volkano-tortul seri, birçok yerde Kuzey Zon'un en alt stratigrafik birimidir ve Schultze-Westrum (1961) tarafindan "Alt Bazik Seri" olarak adlandırılmıştır. Y1lmaz (1984)'e göre, spilit-bazalt, aglomera, tüf ve marnlardan oluşan Liyas yaşlı kayaçlar daha sonra granitler tarafindan kesilmekte ve Senoniyen yaşlı dasit, tüf ve breşlerle uyumsuz olarak örtülmektedir. Bektaş vd. (1987) ise Liyas volkanizmasının bölgenin kuzeyinde bazaltikdasitik volkanizmayla temsil edildiğini ve kuzeydeki havzaların yay içi havzalar özelliğinde olduğunu belirtmiştir.

Doğu Karadeniz Dağları'nın kuzey kesimindeki birimler değişik tip maden yataklarına ev sahipliği yapmaları açısından önem taşırlar. Aslaner ve Gedikoğlu (1984)'ün Harşit yöresindeki çalışmalarına göre, Üst Kretase kayaçları, tabanda piritli dasitik kayaçlarla başlamakta ve üste doğru sırasıyla, volkano-tortul seriyle, hiperstenli-ojitli bazaltlarla, mor ve afanitik dasit ve dasitik tüflerle devam etmektedir. Pontid tipi masif sülfid yataklarının ana kayacını Üst Kretase yaşlı dasit ve bunların piroklastitlerinin oluşturduğu ve bunları hematitli dasit, riyodasit, andezit, bazalt ve bunların piroklastitlerinden oluşan değişik kayaç gruplarının örttüğü ifade edilmiştir. Trabzon ve yakın çevresinde, birbirinden ayrı ve değişik fasiyeslerde gelişmiş kırıntılı çökeller Plio-Kuvaterner yaşlıdır ve bunlar Neojen volkanitlerinin üzerine uyumsuzlukla gelirler (Aydın vd., 2008).

Aydın vd. (2008), Neojen alkali volkaniklerin petrojenez özelliklerini çalışarak, çalışma alanını da içeren Doğu Pontidler'in çarpışma sonrası litosferik incelmesini araştırmıştır. Ersoy vd., (2014), Saraftepe (Trabzon) civarında jeolojik ve jeomekanik özellik araştırması yaparak, bölgeye ait jeolojik yapıları ortaya koymaya çalışmıştır. Maden vd. (2009), ampirik ilişki, güç spektrumu ve gravite ters çözüm tekniklerini gravite verileriyle kullanarak, bölgenin jeolojik yapısını araştırmıştır. Maden (2013), yüzey 1s1 akısı yoğunluğu ve kabuk yapısı verilerini kullanarak, 
bölgenin jeodinamik evrimini anlamaya çalışmıştır. Çavşak ve Elmas (2013), bölgeye ait gravite verilerini kullanarak, ters çözüm tekniği ile bölgedeki tabaka yoğunluklarını ve kalınlıklarını belirlemeye çalışmıştır. Babacan vd. (2014), sismik tomografi ve yüzey dalgası analizi yöntemlerini kullanarak, Trabzon civarındaki volkanik kayaçların evrimini araştırmıştır.

$\mathrm{Bu}$ çalışmada ise bölgeye ait bölgesel gravite verilerinin birinci düşey türev değerleri çeşitli sınır analiz teknikleri ve ters çözüm tekniği ile değerlendirilerek, Trabzon civarındaki sı ğ ve derinde olan muhtemel fay türü yapılar ve çizgisellikler araştırılmıştır.

\section{MATERYAL VE YÖNTEM}

Çalışma alanının içinde bulunduğu bölgenin jeolojisi ve bölgedeki önemli yapısal elemanlar Şekil 1'de, sismik aktivitesi ise Şekil 2'de görülmektedir.

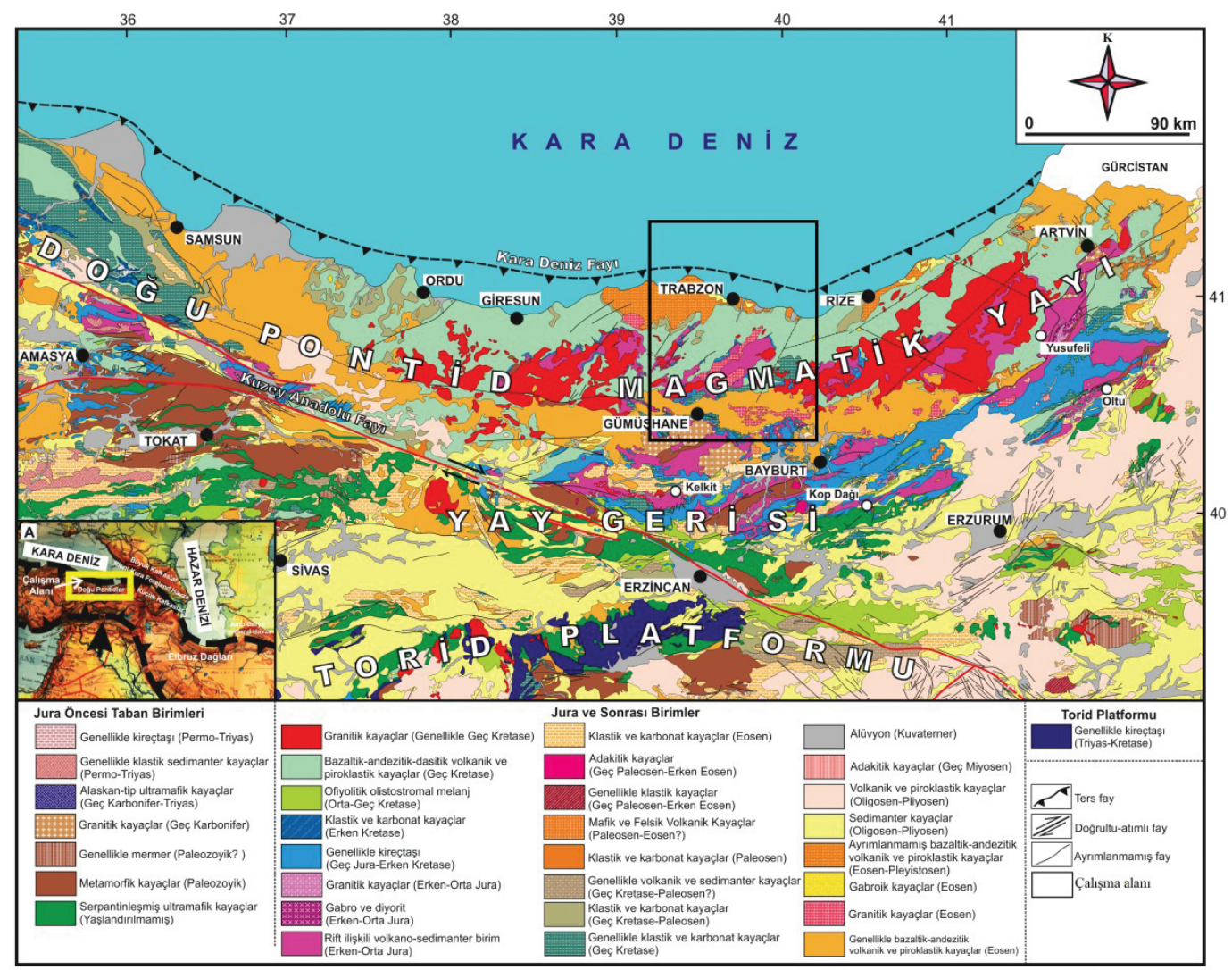

Şekil 1. Çalışma alanı ve çevresin ana tektonik yapıları ve jeolojik birimleri (Eyüboğlu vd., 2007'den düzenlenmiştir).

Figure 1. The main tectonic structures and geological units of the study area and its vicinity (after Eyüboğlu et al., 2007). 
Elmas

Bektaş vd. (1999), Eyüboğlu (2010), Maden (2013), Eyüboğlu vd. (2014) farklı veri setleri kullanarak, çalışma alanını da kapsayan Doğu Pontidler Bölgesi'ndeki fayları araştırmışlardır. Bu çalışmada ise Trabzon ve civarına ait bölgesel gravite verilerinin birinci düşey türev değerleri kullanılarak, bölgeye ait fay türü jeolojik yapılar ve çizgisellikler belirlenmeye çalışılmıştır. türü yapıları ve çizgisellikleri belirlemek için de Arısoy ve Dikmen (2011) tarafından geliştirilen, TYT, AS, EA ve HEA sınır analiz tekniklerini de içeren POTENSOFT programı kullanılmıştır.

Uluslararas1 Sismoloji Merkezi (ISC) veritabanından derlenen, 1996-2016 yıllarına ait moment magnitüdleri 3.0 'dan büyük olan depremlerin dış merkez ve odak derinlik

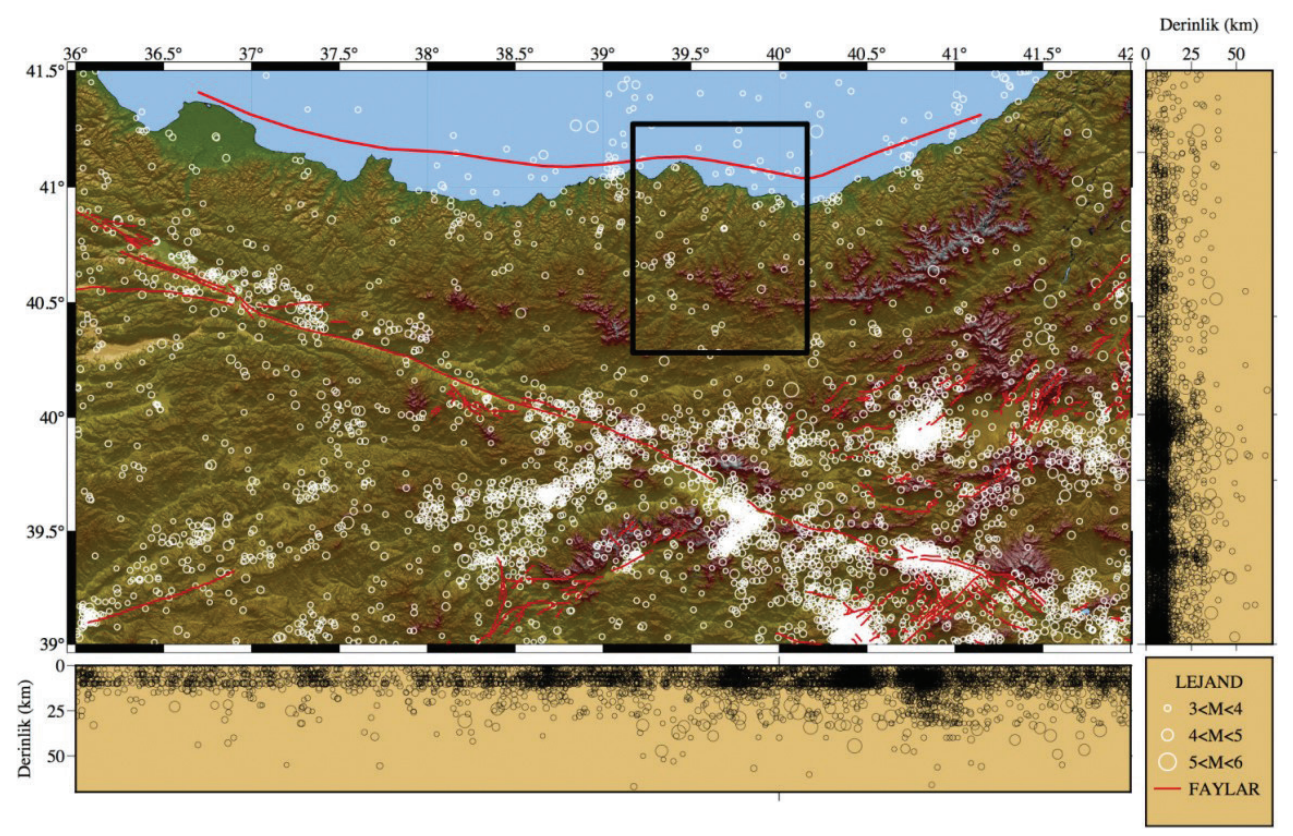

Şekil 2. Çalışma alanı içerisinde 1983-2013 yılları arasında meydana gelen moment magnitüdü 3.0'dan büyük depremlerin dış merkez ve odak derinliği dağılımları. Kırmızı çizgiler MTA’nın güncel fay haritasından derlenen tektonik çizgisellikleri temsil eder. Deprem dağılımları ISC kataloğundan derlenmiştir.

Figure 2. Epicenter and hypocenter distribution of the earthquakes with moment magnitudes greater than 3.0 in the study area between 1983 and 2013. The red lines represent the tectonic lineaments compiled from the MTA's current fault map. Earthquake distributions are compiled from the ISC catalog.

Parker-Oldenburg algoritmas1, temel kaya ara yüzey geometrisini görüntülemek için son zamanlarda yaygın olarak kullanılmaktadır (Oruç vd., 2013; Oruç ve Sönmez, 2017). Bu çalışmada, bölgenin temel kaya topoğrafyasını görüntülemek için bu algoritma kullanılmıştır. Gomez-Ortiz ve Agarwal (2005) bu algoritmay1 Matlab programlama diliyle yazarak geliştirmişlerdir. Çalışma alanındaki yeni fay dağılımları Şekil 2'de görülmektedir. Şekil 2'de, deprem diş merkez dağılımlarının çoğunun fay zonlarında kümelendiği dikkat çekmektedir. Deprem odak derinliklerinin ise ilk $15 \mathrm{~km}$ derinlikte yoğunlaştığ 1 , ancak az da olsa $50 \mathrm{~km}$ derinliğe kadar indiği görülmektedir.

Şekil 3a'da görülen çalışma alanına ait topoğrafya verileri $30 "(1 \mathrm{~km})$ aralıklı 
çözünürlüğü olan Küresel Sayısal Yükseklik Modeli'nden (GTOPO30) (USGS, 1998), Şekil 3b'de görülen çalışma alanına ait Bouguer gravite verileri ise Dünya Gravite Modeli'den (EGM08) elde edilmiştir (Pavlis vd., 2008).

Tektonik yapılarla ilgili olarak minimum gravite değerleri bölgenin güney kısmında, maksimum gravite değerleri ise bölgenin kuzey kısmında görülmektedir (Şekil 3b). Tektonik yapılarla ilişkili olarak, gravite ve topoğrafya değerleri farklı doğrultularda yönelimler sergilemektedir (Şekil 3a ve 3b).
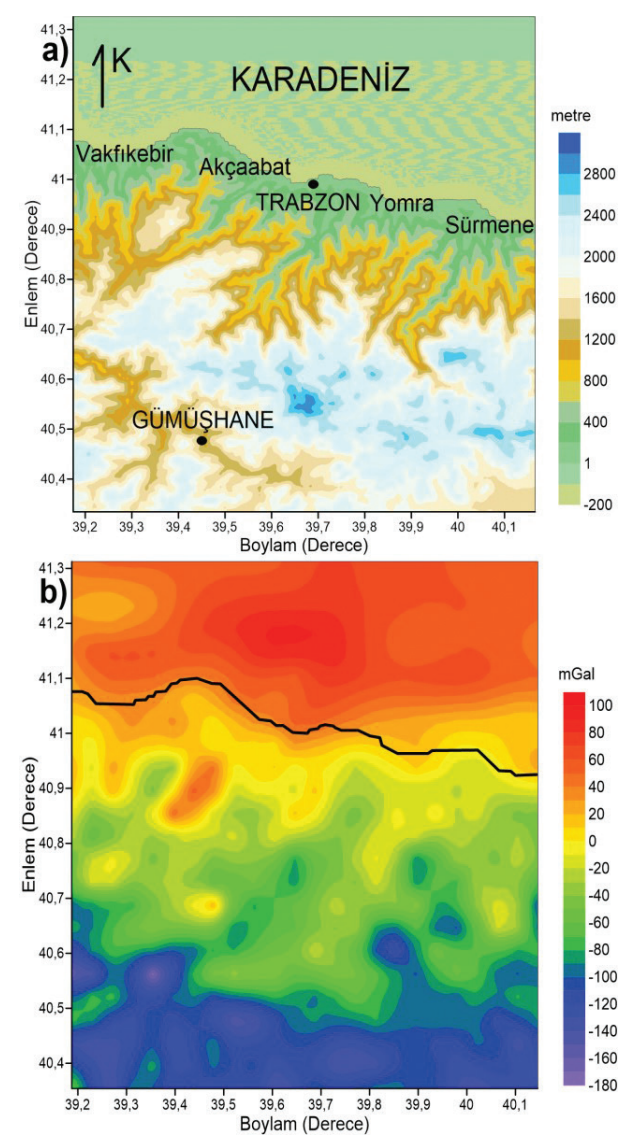

Şekil 3. a) Çalışma alanının topoğrafik haritası ve b) Bouguer gravite haritas1.

Figure 3. a) Topographical map and b) Bouguer gravity map of the study area.
Çalışma alanına ait ara yüzeylerin derinlikleri, ilk olarak Spector ve Grant (1970) tarafından geliştirilen güç spektrumu tekniği kullanılarak belirlenmiştir. $\mathrm{Bu}$ teknik, gravite verilerinin 2B Fourier dönüşümüne bağlıdır. Ara yüzey derinlikleri, dalga sayısı ile gravite verilerinin logaritmik güç spektrumu arasındaki doğrusal ilişkinin eğiminden elde edilir. Hesaplama sonucunda üç farklı ara yüzey derinliği bulunmuştur (Şekil 4). Güç spektrumundan yararlanılarak bulunan derinlikler sirasıyla 2.175 $\mathrm{km}, 5.857 \mathrm{~km}$ ve $10.165 \mathrm{~km}$ ile sediment, temel kaya ve conrad ara yüzeylerine aittir (Şekil 4).

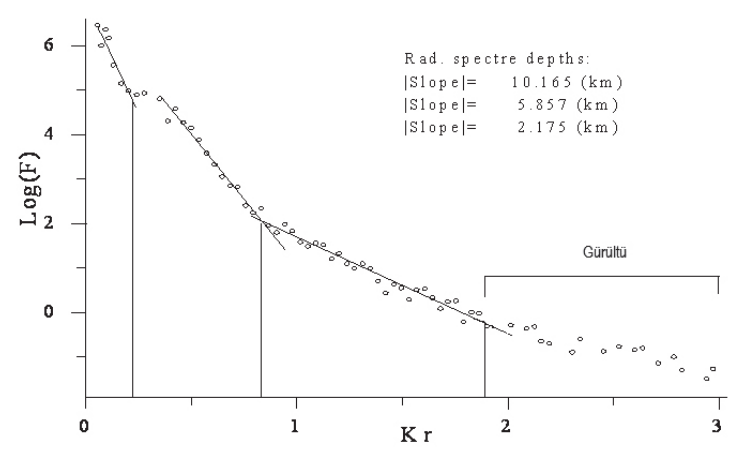

Şekil 4. Çalışma alanına ait gravite verilerinin güç spektrumu.

Figure 4. Power spectrum of the gravity values of the study area.

Güç spektrumu tekniği kullanılarak 5.857 $\mathrm{km}$ derinlik değeri hesaplanan temel kaya ara yüzeyinin topoğrafyasını belirlemek için de Parker-Oldenburg algoritması kullanılmıştır. $\mathrm{Bu}$ algoritma, topoğrafya ara yüzeyinin Fourier dönüşümü ile gravite verilerinin Fourier dönüşümü arasındaki bağıntıya dayanır. $\mathrm{Bu}$ bağıntı, jeolojik yapının bir ara yüzeyinin yoğunluğundan ve belirlenen derinliğinden yinelenerek oluşturulur(Parker, 1973; Oldenburg, 1974). Düzensiz bir homojen tabakanın gravite 
değerlerini hesaplamak için kullanılan Fourier dönüşümü aşağıdaki gibidir:

$$
f\left[z_{1}(x)\right]=-\frac{f[\Delta g(x)] e^{|k| z_{0}}}{2 \pi G \rho}-\sum_{n=2}^{\infty} \frac{|k|^{n-1}}{n !} f\left[z_{1}^{n}(x)\right],
$$

Burada $f[\Delta g(x)], z_{0}, z_{1}(x), k, G$, ve $\rho$ parametreleri, jeolojik yapının ara yüzeyinin sırasıyla gravite değerlerinin Fourier dönüşümü, ortalama derinliği, her ölçü noktası altındaki derinlik, dalga say1s1, gravitasyonal sabiti ve yoğunluğudur. Ara yüzey topoğrafyasının yoğunluğunu hesaplamak için $z_{0}$ ve $\Delta g(x)$ değerleri yinelemeli olarak Formül 1'de kullanılır. Ara yüzey derinliğinin ilk tahmini değeri ters Fourier dönüşümü ile sağlanır. Ayrıca, bu derinlik değeri, Formül 1'in sağ tarafinı bulmak için kullanılır. Böylece, ikinci derinlik değerinin belirlenmesi sağlanır. Yinelemeler yakınsama kriterine ulaşılıncaya kadar devam ettirilir.

\section{Fay Türü Yapıları ve Çizgisellikleri Belirleme Teknikleri}

Literatürde mevcut gravite çalışmalarında, fay türü yapıları ve çizgisellikleri belirlemek için Toplam Yatay Türev (TYT), Analitik Sinyal (AS), Eğim Açısı (EA) ve Hiperbolik Eğim Açısı (HEA) teknikleri genellikle Bouguer gravite verilerine göre düzenlenmiştir (Nabighian, 1972; Miller ve Singh, 1994; Cooper ve Cowan, 2006; Lyngsie vd., 2006). Gravite verilerinin birinci düşey türev değerlerinin kullanımının faydalarını ilk kez Evjen (1936) belirtmiştir. Alçak geçişli süzgeç kullanılmasıyla elde edilen gravite verilerinin birinci düşey türev değerlerinin yorumlanmasında, fay türü jeolojik yapıları görüntülemek için EA tekniğinin ilk kullanımı Oruç ve Keskinsezer (2008) ve
Oruç (2010) tarafından gerçekleştirilmiştir. Bu çalışmada ise yukarıda bahsedilen teknikler, bölgesel gravite verilerinin birinci düşey türev değerlerine uygulanmıştır. Bu sebeple, öncelikle bölgeye ait Bouguer gravite verilerinden bölgesel ve yerel gravite verilerini elde etmek için Butterworth alçak geçişli süzgeç kullanılmıştır. Daha sonra, bölgesel gravite verilerinin birinci düşey türev değerlerini hesaplamak için Hızlı Fourier dönüşümü (FFT) Yöntemi (Gunn, 1975) kullanılmıştır.

Özellikle potansiyel alan verileri ile sı ̆ veya derin faylar arasındaki ilişkiyi görüntüleyebilmek için kullanışlı olan TYT tekniği, Jeolojik yapıların yanal süreksizlik sınırlarını belirleyebilmek için kullanılmaktadır (Lyngsie vd., 2006). TYT'nin genliği, birinci düşey türev değerlerine göre Formül 2'de verildiği gibi ifade edilir:

$$
\mathrm{T}(\mathrm{x}, \mathrm{y})=\sqrt{\left(\frac{\partial^{2} \mathrm{~g}}{\partial \mathrm{x} \partial \mathrm{z}}\right)^{2}+\left(\frac{\partial^{2} \mathrm{~g}}{\partial \mathrm{y} \partial \mathrm{z}}\right)^{2}}
$$

Burada $\frac{\partial^{2} \mathrm{~g}}{\partial \mathrm{x} \partial \mathrm{z}}$ ve $\frac{\partial^{2} \mathrm{~g}}{\partial \mathrm{y} \partial \mathrm{z}}$ terimleri bölgesel gravite verilerinin birinci düşey türev değerlerinin $\mathrm{x}$ ve $\mathrm{y}$ yönlerindeki değişimlerini ifade etmektedir.

AS tekniği potansiyel alan verilerinin yorumlanması için Nabighian (1972) tarafindan kullanılmıştır. Anomaliye sebep olan jeolojik yapılar üzerinde çan şeklinde anomaliler üreten ve yap1 kenarlarında maksimum genlik veren AS tekniği yaygın olarak kullanılır (Nabighian, 1972) ve Formül 3 ’teki gibi tanımlanır:

$$
\mathrm{A}(\mathrm{x}, \mathrm{y}, \mathrm{z})=\sqrt{\left(\frac{\partial^{2} \mathrm{~g}}{\partial \mathrm{x} \partial \mathrm{z}}\right)^{2}+\left(\frac{\partial^{2} \mathrm{~g}}{\partial \mathrm{y} \partial \mathrm{z}}\right)^{2}+\left(\frac{\partial^{2} \mathrm{~g}}{\partial \mathrm{z}^{2}}\right)^{2}}
$$

Burada $\frac{\partial^{2} \mathrm{~g}}{\partial \mathrm{x} \partial \mathrm{z}}, \frac{\partial^{2} \mathrm{~g}}{\partial \mathrm{y} \partial \mathrm{z}}$, ve $\frac{\partial^{2} \mathrm{~g}}{\partial \mathrm{z}^{2}}$ terimleri bölgesel gravite verilerinin birinci düşey türev değerlerinin 
$\mathrm{x}, \mathrm{y}$, ve $\mathrm{z}$ yönlerindeki değişimlerini ifade etmektedir.

Literatürde TYT ve AS tekniklerinin en çok tartışılan zayıf yönü, derin veya düşük yoğunluk sunan yeraltı yapılarına ait kenarlarda düşük genlik sunmaları ve böylece bu yapılara ait kenar etkilerini yeterince yansitamamalarıdır (Miller ve Singh, 1994; Cooper ve Cowan, 2006). Her iki yöntemin bu zayıf noktasından yola çıkan araştırmacılar son yıllarda normalize edilmiş türev yöntemleri başlığı altında teknikler geliştirmişlerdir (Miller ve Singh, 1994; Cooper ve Cowan, 2006). Bu tekniklerden birincisi EA tekniğidir ve hem sı̆̆, hem de derin yapilar için iyi sonuçlar vermektedir (Miller ve Singh, 1994). EA tekniği, yoğunluk farkının güçlü veya zayıf olması durumunda iyi sonuç verir. Eğer yoğunluk farkı pozitifse, EA değerinin işareti anomaliye sebep olan kaynağın üzerinde pozitif, kenarlarında sıfır ve dışında negatif olur. Formül 4'e göre, düşey türevin toplam yatay türeve oranının ark tanjantı, eğim açısı haritasında sıfır değerler üretir. $\mathrm{Bu}$ sıfır değerli konturlar jeolojik birimlerin ve fay tipi yapıların, yoğunluk değişimlerine bağlı olarak yanal süreksizlik sinırlarını temsil etmektedir (Miller ve Singh, 1994).

$$
\varphi=\tan ^{-1}\left(\frac{\frac{\partial^{2} g}{\partial z^{2}}}{\sqrt{\left(\frac{\partial^{2} g}{\partial x \partial z}\right)^{2}+\left(\frac{\partial^{2} g}{\partial y \partial z}\right)^{2}}}\right)
$$

Burada $\varphi$ parametresi EA'nın genliğini temsil eder.

$\mathrm{Bu}$ çalışmada kullanılan son teknik, Cooper ve Cowan (2006) tarafindan, jeolojik yapıların yanal süreksizlik sınırlarının etkin bir şekilde belirlenebilmesi için önerilen HEA tekniğidir. Formül 5'te gösterildiği gibi bu teknikte, EA tekniğinden farklı olarak düşey türev ve toplam yatay türev değerlerinin oranları hiperbolik olarak ifade edildiğinden, sonuç açısal değil, skaler bir büyüklüktür. HEA tekniği de EA tekniğine benzer biçimde hem sı $\breve{g}$, hem de derin jeolojik yapıların yanal süreksizlik sınırlarını belirlemede iyi sonuçlar verir (Cooper ve Cowan, 2006). EA tekniğinde olduğu gibi bu teknikte de eğer yoğunluk farkı pozitifse, HEA değerinin işareti anomaliye sebep olan kaynağın üzerinde pozitif, kenarlarında sıfır ve dışında negatif olur (Cooper ve Cowan, 2006).

$$
\mathrm{H} \varphi=\mathrm{R}\left[\tanh ^{-1}\left(\frac{\frac{\partial^{2} \mathrm{~g}}{\partial \mathrm{z}^{2}}}{\sqrt{\left(\frac{\partial^{2} \mathrm{~g}}{\partial \mathrm{x} \partial \mathrm{z}}\right)^{2}+\left(\frac{\partial^{2} \mathrm{~g}}{\partial \mathrm{y} \partial \mathrm{z}}\right)^{2}}}\right)\right]
$$

Burada $\mathrm{R}$ reel bileşen ve $\mathrm{H} \varphi$ ise HEA'nın genliğidir.

Şekil 5c'de, yoğunluk farkları aynı $(0.3 \mathrm{~g} /$ $\mathrm{cm}^{3}$ ) olan farklı derinlik ve boyutlara sahip beş dikdörtgen cisimden oluşan sentetik model görülmektedir. Sentetik modelin etkilerini, çizgisel yapıları belirlemede kullanılan teknikler üzerinde görmek için, Arısoy ve Dikmen (2011) tarafından geliştirilen POTENSOFT yazılımı kullanılmıştır. Cisimler aynı yoğunluk farkına sahip olmalarına rağmen, yüzeyden olan derinlikleri sirasiyla 1, 3, 5, 7 ve $9 \mathrm{~km}$ olarak tasarlanmıştır(Şekil 5c). Bu modelden hesaplanan gravite haritası Şekil 5a'da görülmektedir. Hesaplanan gravite verilerinin birinci düşey türev haritası ise Şekil 5b'de görülmektedir. Şekil 5a ve 5 b karşılaştırıldığında, farklı derinliklerdeki cisimlerin konumlarını görüntüleme işleminde, türev haritasının gravite haritasına göre daha başarılı sonuç verdiği görülmektedir. Daha sonra ise, TYT, AS, EA ve HEA teknikleri, sentetik modelden hesaplanan gravite verilerinin birinci düşey türev değerleri ile test edilmiştir. 

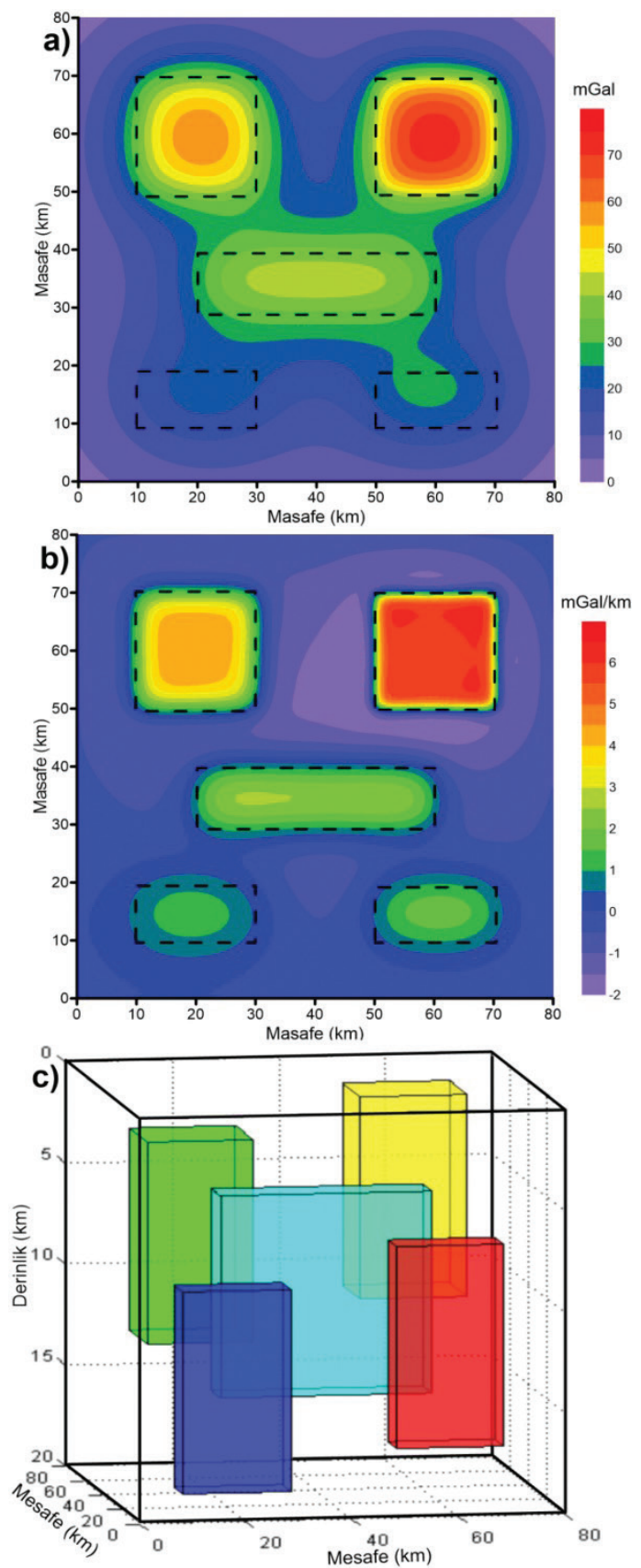

Şekil 5. a) Sentetik modelin gravite haritas1, b) gravite verilerinin birinci düşey türev haritası, c) sentetik modelin şematik gösterimi.

Figure 5. a) The gravity map of the sythetic model, b) the first vertical derivative map of the gravity values, $c$ ) schematic presentation of the model.
Şekil 6a'daki TYT tekniğinin sonucuna göre, sığ cisimlerin yanal süreksizlik sinırları iyi bir biçimde görüntülenebiliyorken, cismin derinliği arttıkça bu netliğin azaldığ 1 görülmektedir. TYT tekniğinin doğasından dolayı, cismin derinliği arttıkça, maksimum genlikte hızlı bir azalma olur (Şekil 6a). Böylece bu tekniğin sığ cisimlere daha duyarlı olduğu anlaşılmaktadır. Başka bir deyişle, sarı ve yeşil renkli cisimler diğer cisimlere göre daha kolay görüntülenmiştir (Şekil $5 \mathrm{c}$ ve 6a). Bu çalışmada kullanılan ikinci sınır analiz tekniği olan AS tekniği, TYT tekniğindekine benzer sonuçlar verirken, AS haritası sı̆̆ cisimlerin sınırları boyunca kümelenme formları sunmaktadır. $\mathrm{Bu}$ tekniğin kullanılmasıyla da, TYT tekniğine benzer olarak, sı̆̆ cisimlerin yanal süreksizlik sınırları görüntülenebiliyorken, derin cisimlerin sınırlarının iyi bir şekilde belirlenemediği görülmüştür (Şekil 6b). EA ve HEA tekniklerinin sonuçları Şekil $6 \mathrm{c}$ ve $6 \mathrm{~d}$ 'de görülmektedir. Bu iki tekniğin genlik haritalarına bakıldığında, cisimlerin sınırları üzerinde sıfır genlik değerleri görülür. EAve HEA teknikleriyle, cisim derinlikleri değişmesine rağmen, hem sı̆̆ hem de derinde olan cisimlerin sınırları gerçeğe yakın olarak belirlenmiştir. 

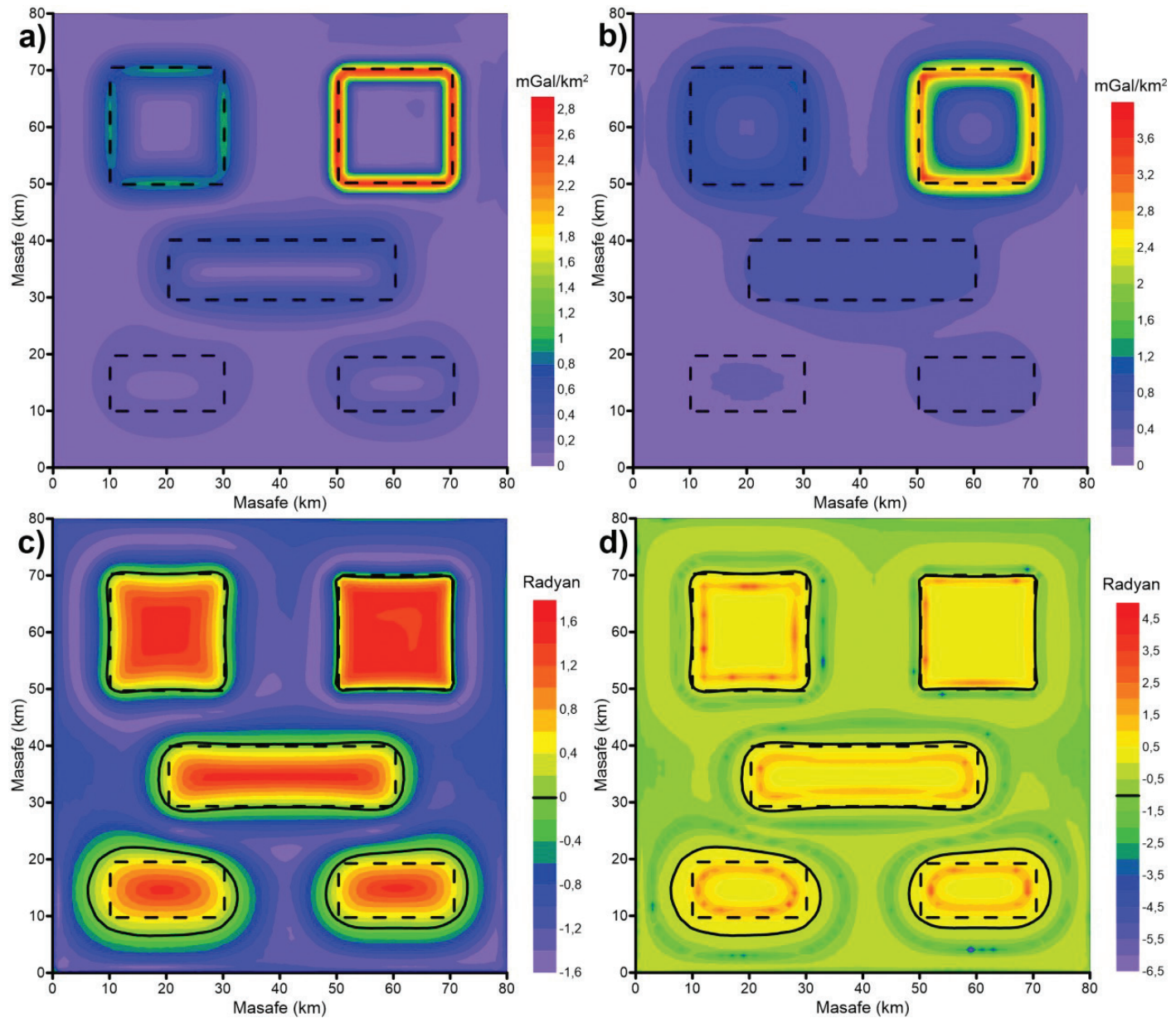

Şekil 6. Sentetik modelin; a) TYT haritası, b) AS haritası, c) EA haritası, d) HEA haritası.

Figure 6. a) Horizontal gradient, b) analytic signal, c) tilt angle, d) hyperbolic of tilt angle maps of the synthetic model.

\section{Çalışma Alanı Verileriyle Yapılan Çalışmalar}

Bölgeye ait topoğrafya, Bouguer gravite ve bölgesel gravite verilerinin birinci düşey türev değerlerinin, çizgisel belirti verebilecek yapılarla ve bölgenin temel kaya topoğrafyasıyla ilişkili olarak doğu-batı, kuzey-güney ve kuzeydoğugüneybatı doğrultulu uzanımlar sergiledikleri görülmektedir (Şekil 3a, 7a ve 7d). Tabaka kalınlıklarındaki azalmaya bağlı olarak gravite değerleri güneyden kuzeye doğru artmaktadır.

Bölgede çizgisellik gösteren yapıları belirleyebilmek için temel kaya topoğrafyasının belirlenmesi oldukça önemlidir. Çalışma alanını da içine alan Doğu Pontidler Bölgesi'nde temel kaya topoğrafyasının derinliğinin, güç spektrumu kullanılarak $4.1 \mathrm{~km}$ ile $6.2 \mathrm{~km}$ arasında değiştiği belirlenmiştir (Maden, 2013). Bölgedeki depremler genellikle ilk $15 \mathrm{~km}$ derinde oluştukları için bu sonuç bölgenin sismisitesiyle uyumludur (Şekil 2). Bölgenin bölgesel gravite anomalisinin elde edilmesi için alçak geçişli süzgeç kullanılmıştır. Bouguer gravite, bölgesel gravite, yerel gravite ve bölgesel gravitenin birinci düşey türev haritaları sırasıyla Şekil 7a, $7 \mathrm{~b}, 7 \mathrm{c}$ ve $7 \mathrm{~d}$ 'de görülmektedir. 
Elmas
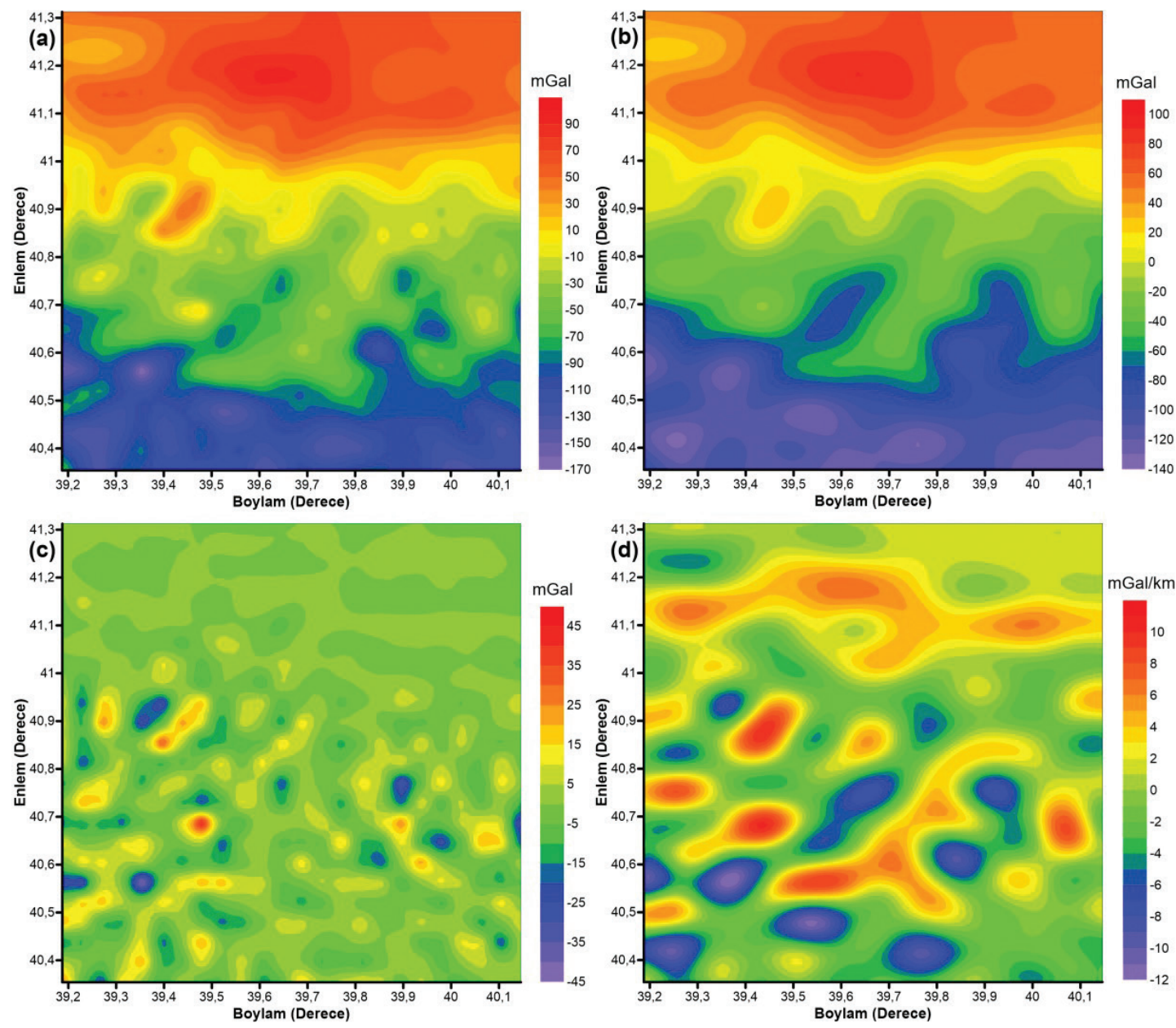

Şekil 7. a) Bouguer gravite haritası, b) bölgesel gravite haritas1, c) yerel gravite haritas1, d) bölgesel gravite verilerinin birinci düşey türev haritas1.

Figure 7. a) The gravity map, b) the regional gravity map, c) local gravity map, d) the first vertical derivative map of the regional gravity values.

Bölgesel gravite verilerinin birinci düşey türev değerlerinden hesaplanan TYT ve AS genliklerinin maksimum değerleri ile EA ve HEA genliklerinin sıfır değerleri, çalışma alanındaki tektonik süreksizlikleri ve çizgisellikleri gösteren yapıları temsil etmektedir. 

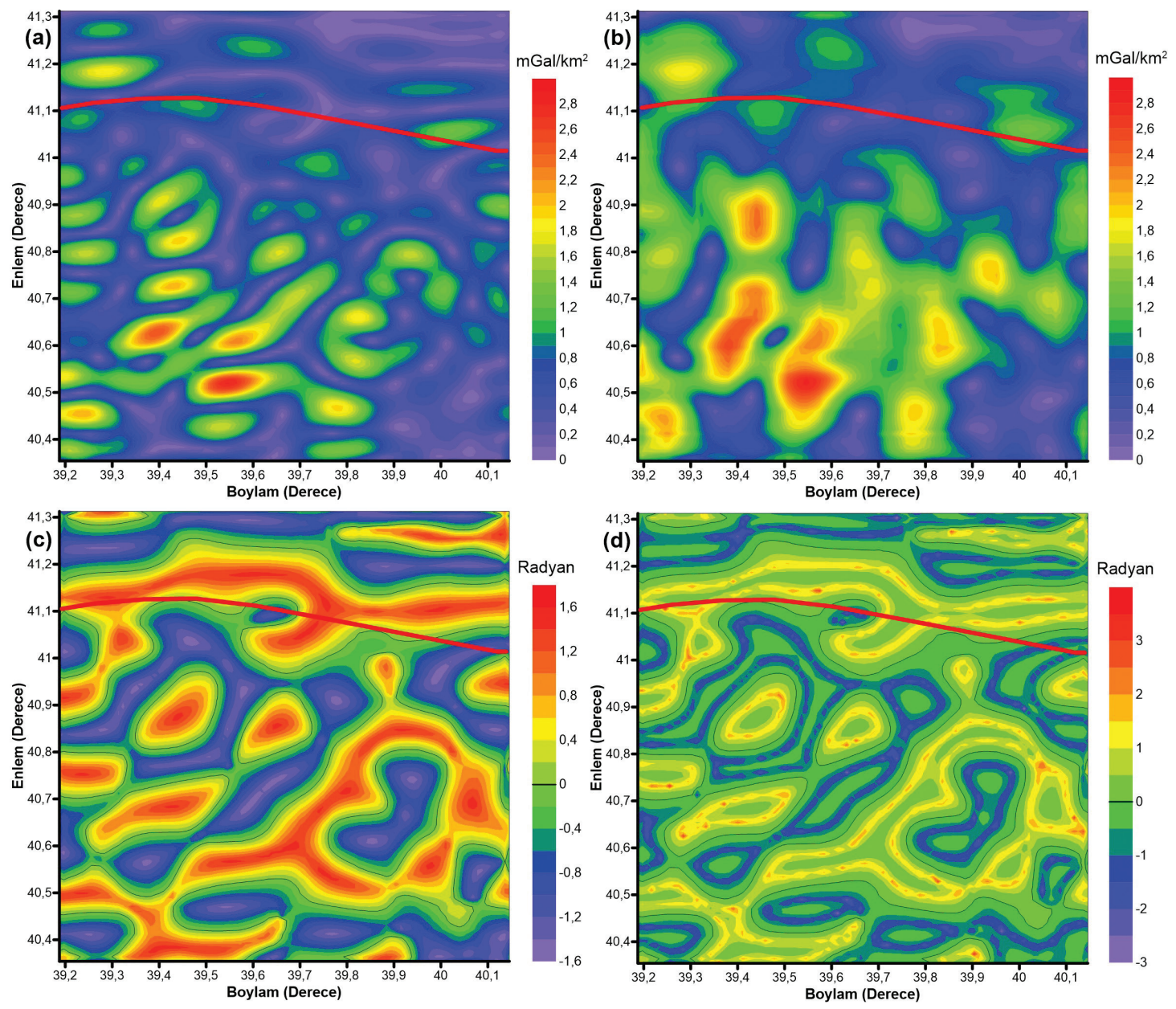

Şekil 8. Çalışma alanının; a) TYT haritası, b) AS haritası, c) EA haritası, d) HEA haritası. (Kırmızı çizgi Karadeniz'de sahile yakın olan bilinen faydir (ISC)).

Figure 8. a) The horizontal gradient map, b) the analytic signal map, c) the tilt angle map, d) the hyperbolic of tilt angle map of the region. (Red line represents the known fault of the region (ISC) close to the coast).

TYT ve AS'nin maksimum genlik değerleri tektonik süreksizliklerin doğu-batı, kuzey-güney ve kuzeydoğu-güneybatı doğrultulu uzanımlar sergilediklerini göstermektedir (Şekil 8a ve 8b). TYT ve AS sonuçları, çalışma alanında çizgisellik gösteren sığ yapıları gösterir. Böylece, çalışma alanının bazı kısımlarındaki yeni fay türü yapılar ve yoğunluk fark1 sunan kütle sınırları, TYT ve AS haritalarında görülebilir. EA ve HEA haritalarına bakıldığında, çizgisellik gösteren hem derin hem de sı̆̆ yapılar üstünde sıfır genlik değerleri görülmektedir (Şekil 8c ve $8 d$ ). Bu yapılar da doğu-batı, kuzey-güney ve kuzeydoğu-güneybatı doğrultulu uzanımlar sergilemektedir.

Altın ve gümüş mineralleri gibi ekonomik değeri olan birçok maden yatağı ağırlıklı olarak tektonik süreksizlikler ile yakın ilişkili oldukları için (Ercan vd., 2014), çalışma 
Elmas

alanındaki maden yataklarının yerleri ve yeni bulunmuş çizgiselliklerin uzanımları gözlemsel olarak karşılaştırılmıştır. Uzun zaman boyunca oluşmuş olan maden yataklarının varlığ belirlenen fay türü yapıların varlığgnı gözlemsel olarak kısmen destekler niteliktedir. $\mathrm{Bu}$ sonuç MTA'dan temin edilen Türkiye mineral yatakları haritasından derlenen haritada (Şekil 9a) ve bu çalışma kapsamında elde edilen çizgisellik haritasında (Şekil 9c) görülmektedir. Ayrıca yeni belirlenen fay türü yapıların varlığını, alanda önceden yaşanmış depremlerin diş merkez dağılımları da gözlemsel olarak kısmen destekler niteliktedir (Şekil 2). Yani çizgisel yapıların bazıları aktif fayları, bazıları eski (paleotektonik) fayları ve bazıları da yoğunluk farkı sunan kütle sınırlarını temsil etmektedir. Önceden varlığ 1 bilinen ve bu çalışma kapsamında belirlenen çizgisel yapılar Şekil 9b ve 9c'de görülmektedir.

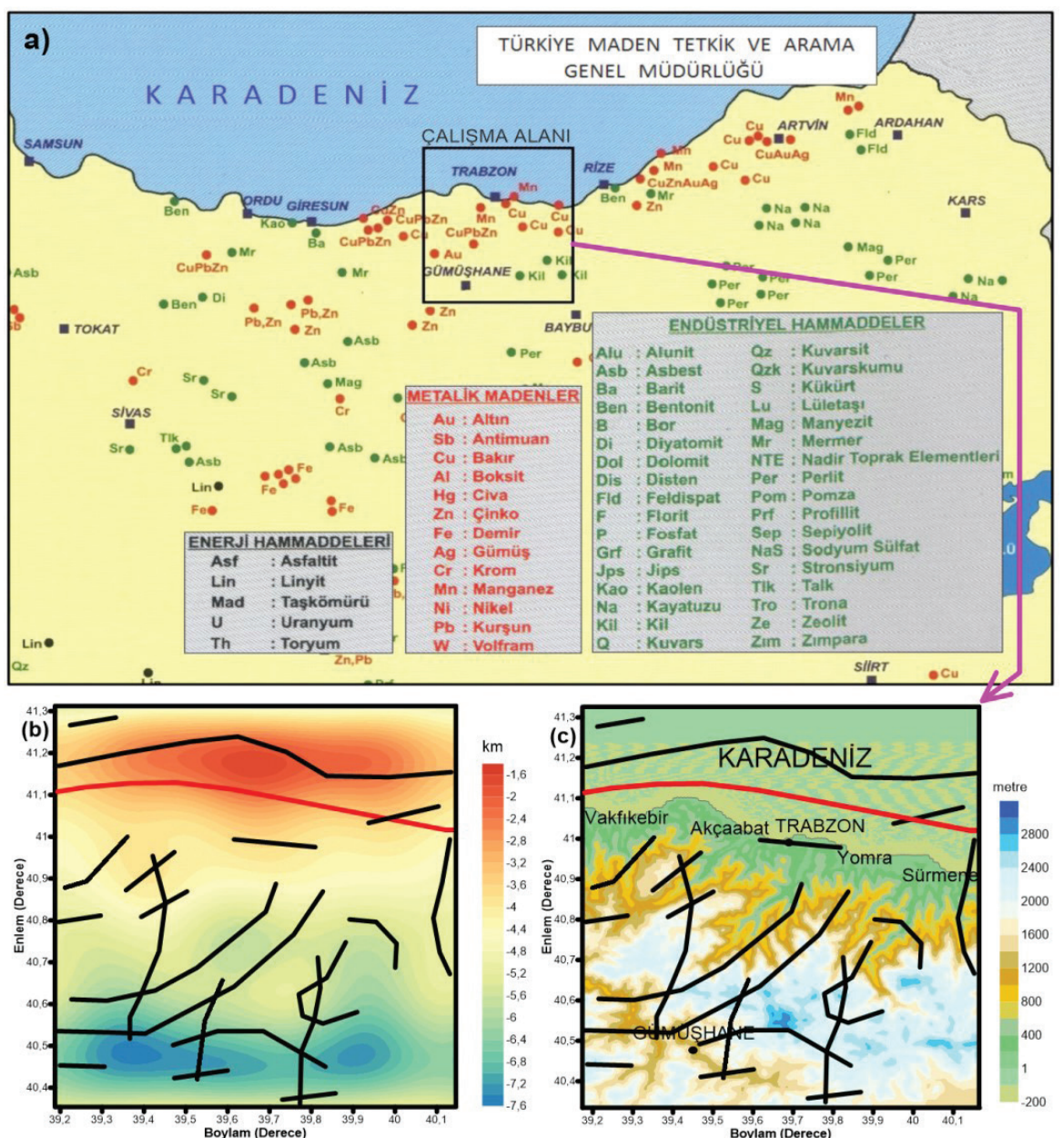

Şekil 9. a) Çalışma alanı ve civarının maden yatakları haritası (MTA'dan derlenmiştir). b) çalışma alanının temel kaya topoğrafya haritası, c) çalışma alanının topoğrafik haritası (kırmızı çizgi mevcut fayı ve siyah çizgiler de çizgisel yapıları temsil etmektedir). Figure 9. a) Mineral deposits map of the area (compiled from MTA) b) basement map of study area c) topographical map of the study area (red line represents existing fault and black line represents linear structures). 
Çalışma alanına ait bölgesel gravite verileri ve Parker-Oldenburg algoritmas1 kullanılarak, temel kaya topoğrafyası yinelemeli olarak hesaplanmıştır (Şekil 9b). Temel kaya topoğrafyasını hesaplamak için başlangıç derinliği değeri $5.857 \mathrm{~km}$ olarak kullanılmıştır. Metamorfik birim $\left(\sim 2.7 \mathrm{~g} / \mathrm{cm}^{3}\right)$ ile temel kaya derinliğine kadar olan Neojen sedimentleri $\left(\sim 2.4 \mathrm{~g} / \mathrm{cm}^{3}\right)$ arasındaki yoğunluk farkı $0.3 \mathrm{~g} /$ $\mathrm{cm}^{3}$ olarak belirlenmiştir. Yakınsama kriteri olarak $0.01 \mathrm{~km}$ seçilmiştir. Kesme dalgası sayıları, güç spektrumundan sırasıyla $0.06 \mathrm{~km}^{-1}$ ve $0.28 \mathrm{~km}^{-1}$ olarak belirlenmiştir. RMS hatası ve yineleme sayıs1 sirasiyla $0.0024 \mathrm{~km}$ ve 5'tir. Bölgesel gravite verileri ile hesaplanan temel kaya topoğrafyası arasında kuvvetli bir ilişki görülmektedir (Şekil 7b ve 9b). Antiklinalleri ve senklinalleri takip eden çizgisellikler, temel kaya topoğrafyasını kontrol etmektedir. Temel kaya topoğrafyasındaki alçalma ve yükselimlerdeki antiklinaller ve senklinaller arasındaki sinırların fay zonlarıyla ilişkili olmalarından dolayı (Oruç vd., 2013), bu gözlem beklentilerle uyumludur. Temel kaya topoğrafyasının en sığ yeri $1.6 \mathrm{~km}$ ile bölgenin kuzey kısmında iken, en derin yeri ise $7.6 \mathrm{~km}$ ile güney kısmındadır. Temel kaya topoğrafyasındaki alçalma ve yükselimlerin faylarla k1smen uyumlu olduğu görülmektedir (Şekil 9b).

\section{TARTIŞMALAR}

TYT, AS, EA ve HEA sinır analiz teknikleri kullanılarak, çalışma alanında yeni fay türü yapılar ve çizgisellikler belirlenmiştir. $\mathrm{Bu}$ çalışmada kullanılan teknikler literatürde mevcuttur, fakat çalışma alanının bölgesel gravite verilerinin birinci düşey türev değerlerine bu teknikler ilk kez uygulanmıştır. Çalışma alanının bazı kısımlarında TYT ve AS haritalarında maksimum genlik görülmezken,
EA ve HEA haritalarında aynı kisımlarda sifir genlik değerleri görülmüştür (Şekil $8 \mathrm{a}, 8 \mathrm{~b}, 8 \mathrm{c}$ ve $8 \mathrm{~d}$ ). Çalışma alanındaki fay türü yapıların ve çizgiselliklerin temel kaya topoğrafyasıyla, maden yataklarının dağılımıyla ve alanda daha önce yaşanmış depremlerin dış merkez dağılımlarıyla ilişkisi gözlemsel olarak kısmen görülebilmektedir. Bektaş vd. (1995), Eyüboğlu vd. (2006), Maden vd. (2009) çalışma alanını da içine alan Doğu Pontidler Bölgesi'ndeki üç alt zonun sınırlarını belirlemişler, ancak bu çalışmada bulunan daha alt birimlerin neden olduğu çizgiselliklere değinmemişlerdir. Yeni bulunan faylar ve çizgisellikler Şekil 9b ve 9c'de açıkça görülmektedir. Maden vd. (2009) güç spektrumu tekniğini kullanarak, çalışma alanını da içine alan Doğu Pontidler Bölgesi'nin temel kaya topoğrafyasının derinliğinin $4.1 \mathrm{~km}$ ile 6.2 $\mathrm{km}$ arasında değiştiğini bulmuştur. Bu çalışmada ise, Parker-Oldenburg algoritması kullanılarak Doğu Pontidler Bölgesi'nin kuzey kısmında yer alan çalışma alanının temel kaya topoğrafyası derinliğinin kuzeyden güneye doğru $1.6 \mathrm{~km}$ ile 7.6 $\mathrm{km}$ arasında değiştiği ortaya konmuştur. Maden (2013) yüzey 1s1 akıs1 yoğunluğu ve kabuk yapıs1 verilerini kullanarak, Çavşak ve Elmas (2013) ise bölgeye ait gravite verilerini kullanarak çalışma alanını da içine alan Doğu Pontidler Bölgesi'ndeki jeolojik yapıları belirlemeye çalışmışlar, fakat bu çalışmada bulunan yeni fay türü yapılardan ve çizgiselliklerden bahsetmemişlerdir. Yine birçok araştırmacı (Barazangi vd., 2006; Pamukçu vd., 2007; Maden ve Öztürk, 2015) çalışma alanını da içine alan Doğu Pontidler Bölgesi'nde çeşitli veri setleri kullanarak bazı çalışmalar yapmış, ancak bu araştırmacılar da, bu çalışmada bahsedilen çizgiselliklere değinmemişlerdir.

Literatürde mevcut olan, fay türü yapıları belirlemek için yapılmış gravite alanındaki çalışmalarda TYT, AS, EA ve HEA sınır analiz teknikleri genellikle Bouguer gravite verileriyle 
kullanılmıştır (Nabighian, 1972; Miller ve Singh, 1994; Cooper ve Cowan, 2006; Lyngsie vd., 2006). Bu çalışmada ise bu teknikler bölgesel gravite verilerinin birinci düşey türev değerleriyle kullanılmıştır. Çalışmada, temel kaya topoğrafyasındaki antiklinal ve senklinallerle ilgili olarak yükselim ve alçalma bölgeleri de belirlenmiştir (Şekil 9b).

Bölge, çarpışma kuşağı içinde olmasının dışında hem yüzeyde hem de derinde yoğun magmatik faaliyet olmasindan dolayı, her bir magmatik kütle veya sokulum doğal olarak farklı gravite anomalisi üretir. Bu kütlelerin yan kayaçlar ile dokanaklarını faylardan ayırt etmek için, bu çalışmanın sonuçlarından yararlanılarak daha farklı çalışmalar yapılmalıdır. Ayrıca sınır analiz teknikleriyle belirlenen fay zonlarının paleotektonik yap1 m1, yoksa neotektonik veya aktif yapı mı olduğu ayrı bir araştırma konusudur. Yine bu çalışmadan elde edilen sonuçlar kullanılarak yapılacak farklı çalışmalarla bu konu aydınlatılmalıdır.

\section{SONUÇLAR VE ÖNERÍLER}

Tektonik yapısı, maden yatakları ve büyük faylara yakınlığı ile Trabzon ve çevresi önemli bir bölgedir. Öte yandan, çalışma alanı ve yakın çevresi eski çağlardan beri birçok deprem yaşamıştır. $\mathrm{Bu}$ çalışmada, Trabzon çevresinin yeni fay ve çizgisellik haritası verilmiştir. Kullanılan teknikleri birbiriyle karşılaştırmak için farklı boyutlara ve derinliklere sahip olan beş farklı dikdörtgen prizma kullanılarak oluşturulan sentetik model kullanılmıştır. Çalışma alanının temel kaya topoğrafyası da modellenmiştir. Dört farklı teknik kullanılarak yeni fayların ve çizgiselliklerin yerleri, TYT ve AS haritalarının maksimum genlik değerleri ve EA ve HEA haritalarının da sifir konturları kullanarak belirlenmiştir. Bölgede var olan ancak geleneksel yöntemlerle şu ana kadar tespit edilemeyen bazı yeni faylar ve çizgisellikler başarıyla tespit edilmiştir. Belirlenen yeni faylar ve çizgisellikler ile maden yataklarının dağılımları ve deprem dış merkez dağılımları arasında gözlemsel olarak belirli oranda uyum görülmüştür.

Belirlenen çizgiselliklerin, yoğunluk farkına sahip sokulum yapmış kütlelerin dokanaklarını $\mathrm{m} 1$, yoksa yeni fayları $\mathrm{m} 1$ temsil ettiği, eğer ediyor ise bu fayların paleotektonik yapı $\mathrm{m} 1$, neotektonik veya aktif yapı $\mathrm{m}$ olup olmadığı, bu çalışmanın sonuçlarından faydalanılarak yapılacak olan yeni çalışmalarla aydınlatılmalıdır. $\mathrm{Bu}$ çalışmanın sonuçları, gelecekte yapılacak olan detaylı jeofizik çalışmalarla desteklenmelidir. Böylece, çalışma alanında var olup ancak henüz keşfedilmemiş maden yataklarını ve deprem riski yüksek olan yerleri belirlemek daha kolay olacaktır.

\section{KATKI BELIRTME}

Yazar, bu çalışmadaki katkılarından dolayı, Karadeniz Teknik Üniversitesi'nden Prof. Dr. Yener EYÜBOĞLU'na, Prof. Dr. Faruk AYDIN‘a ve Kocaeli Üniversitesi’nden Prof. Dr. Bülent ORUÇ'a; çalışma alanına ait deprem iç ve dış merkez dağılım haritasının hazırlanmasında yardımcı olan Kocaeli Üniversitesi'nden Dr. Deniz CAKA'ya, maden yatakları haritasını sağlayan MTA'dan Yük. Müh. Kürşat BEKAR'a çok teşekkür eder.

\section{KAYNAKLAR}

Akaryal1, E., Tüysüz, N., 2013. The genesis of the slab window-related Arzular low sulfidation epithermal gold mineralization (eastern Pontides, NE Turkey). Geoscience Frontiers, 4, 409-421.

Arısoy, M. Ö., Dikmen, Ü., 2011. Potensoft: MATLAB-based Software for potential field data 
processing, modelling and mapping. Computer \& Geosciences, 37, 935-942.

Aslaner, M., Gedikoğlu, A., 1984. Harşit Vadisi (Tirebolu-Giresun) metalik cevherleşme tipleri. Karadeniz Teknik Üniversitesi Jeoloji Dergisi, 3 (1-2), 1-15.

Aydın, F., Karsli, O., Chen, B., 2008. Petrogenesis of the Neogene alkaline volcanics with implications for post-collisional lithospheric thinning of the Eastern Pontides, NE Turkey. Lithos, 104, 249266.

Babacan, A. E., Gelisli, K., Ersoy, H., 2014. Seismic Tomography and Surface Wave Analysis Based Methodologies on Evaluation of Geotechnical Properties of Volcanic Rocks: A Case Study. Journal of Earth Science, 25 (2), 348-356.

Barazangi, M., Sandvol, E., Seber, D., 2006. Structure and tectonic evolution of the Anatolian plateau in eastern Turkey. In: Dilek, Y., Pavlides, S. (Eds.), Post-collisional Tectonics and Magmatism in the Mediterranean Region and Asia. Geological Society of America Bulletin, 409, 463-474.

Bektaş, O., Van, A., Boynukalın, S., 1987. Doğu Pontidler'de (Kuzeydoğu Türkiye) Jura volkanizması ve jeotektoniği. Türkiye Jeoloji Bülteni, 30, 9-19.

Bektaş, O., Yılmaz, C., Taslı, K., Akdağ, K., Özgür, S., 1995. Cretaceous rifting of the eastern Pontide carbonate platform (NE Turkey): the formation of carbonates breccias and turbidites as evidences of a drowned platform. Geologia, 57 (1-2), 233-244.

Bektaş, O., Şen, C., Atıcı, Y., Köprübaşı, N., 1999. Migration of the Upper Cretaceous subductionrelated volcanism toward the back-arc basin of the eastern Pontide magmatic arc (NE Turkey). Geological Journal, 34, 95-106.

Cooper, G. R. J., Cowan, D. R., 2006. Enhancing potential field data using filters based on the local phase. Computers and geosciences, 32 (10), 1585-1591.
Çavşak, H., Elmas, A., 2013. Determining crustal structure and density in the Eastern Black Sea and Pontide Mountains using 3D gravity model calculations. Carbonates and Evaporites, DOI: 10.1007/s13146-013-0161-6.

Ercan, Ö. A., Şeren, A., Elmas, A., 2014. Gold and silver prospection using Magnetic, Radiometry and Microgravity Methods in the Kışladağ province of Western Turkey. Resource Geology, DOI: $10.1111 /$ rge. 12024 .

Evjen, H. M., 1936. The place of the vertical gradient in gravitational interpretations. Geophysics, 1, 127-136.

Ersoy, H., Yalçınalp, B., Babacan, A. E., 2014. Investigation of geological and geomechanical properties of the Saraftepe (Trabzon) tephritic sill. Journal of Geological Engineering, 38 (1), $39-50$.

Eyüboğlu, Y., 2010. Late Cretaceous high-K volcanism in the eastern Pontides orogenic belt, and its implications for the geodynamic evolution of NE Turkey. International Geology Review, 52 (2-3), 142-186.

Eyüboğlu, Y., Bektaş, O., Pul, D., 2007. MidCretaceous olistostromal ophiolitic melange developed in the back-arc basin of the eastern Pontide magmatic arc (NE Turkey). International Geology Review, 49 (12), 1103-1126.

Eyüboğlu, Y., Bektaş, O., Seren, A., Maden, N., Jacoby, W. R., Özer, R., 2006. Three axial extensional deformation and formation of the Liassic rift basins in the Eastern Pontides (NE Turkey). Geologica Carpathica, 57 (5), 337-346.

Eyüboğlu, Y., Santosh, M., Yi, K., Tüysüz, N., Korkmaz, S., Akaryal1, E., Dudas, F., Bektaş, O., 2014. The Eastern Black Sea-type volcanogenic massive sulfide deposits: geochemistry, zircon $\mathrm{U}-\mathrm{Pb}$ geochronology and an overview of the geodynamics of ore genesis. Ore Geology Reviews, 59, 29-54. 
Elmas

Gomez-Ortiz, D., Agarwal, B. N. P., 2005. 3DINVER.M: A MATLAB program to invert the gravity anomaly over a 3-D horizontal density interface by Parker-Oldenburg's algorithm. Computer Geosciences, 31, 513-520.

Gunn, P. J., 1975. Linear transformations of gravity and magnetic fields. Geophysical Prospecting, 23 (2), 300-312.

Lyngsie, S. B., Thybo, H., Rasmussen, T. M., 2006. Regional geological and tectonic structures of the North Sea area from potential field modelling. Tectonophysics, 413 (3-4), 147-170.

Maden, N., Gelişli, K., Bektaş, O., Eyüboğlu, Y., 2009. Two-and-three-dimensional crust topography of the Eastern Pontides (NE Turkey). Turkish Journal of Earth Sciences, 18, 225-238.

Maden, N., 2013. Geothermal structure of the eastern Black Sea basin and the eastern Pontides orogenic belt: Implications for subduction polarity of Tethys oceanic lithosphere. Geoscience Frontiers, 4, 389-398.

Maden, N., Öztürk, S., 2015. Seismic b-Values, Bouguer Gravity and Heat Flow Data Beneath Eastern Anatolia, Turkey: Tectonic Implications. Survey in Geophysics, 36, 549-570.

Miller, H. G., Singh, V., 1994. Potential field tilt -a new concept for location of potential field sources. Journal of Applied Geophysics, 32, 213-217.

Nabighian, M. N., 1972. The Analytic Signal of two dimensional magnetic bodies with polygonal cross section: Its properties and use for automated anomaly interpretation. Geophysics, $37,507-517$.

Oldenburg, D. W., 1974. The inversion and interpretation of gravity anomalies. Geophysics, 39, 526-536.

Oruç, B., Keskinsezer, A., 2008. Structural setting of the northeastern Biga Peninsula (Turkey) from tilt derivatives of gravity gradient tensors and magnitude of horizontal gravity components. Pure Applied Geophysics, 165, 1913-1927.
Oruç, B., Sertçelik, İ., Kafadar, Ö., Selim, H. H., 2013. Structural interpretation of the Erzurum Basin, Eastern Turkey, using curvature gravity gradient tensor and gravity inversion of basement relief. Journal of Applied Geophysics, 88,105-113.

Oruç, B., Sönmez, T., 2017. The rheological structure of the lithosphere in the Eastern Marmara region, Turkey. Journal of Asian Earth Sciences, 139, 183-191.

Oruç, B., 2010. Edge detection and depth estimation using a tilt angle map from gravity gradient data of the Kozakl1-Central Anatolia Region, Turkey. Pure and Applied Geophysics, DOI: 10.1007/ s00024-010-0211-0.

Pamukçu, O. A., Akçıg, Z., Demirbaş, Ş., Zor, E., 2007. Investigation of crustal thickness in eastern Anatolia using gravity, magnetic and topographic data. Pure and Applied Geophysics, $164,2345-2358$.

Parker, R. L., 1973. The rapid calculation of potential anomalies. Geophysical Journal International, 31, 447-455.

Pavlis, N. K., Holmes, S. A., Kenyon, S. C., Factor. J. K., 2008. An Earth Gravitational Model to Degree 2160: EGM2008. EGU General Assembly 2008, Vienna, Austria, April 13-18, 2008. http://earth-info.nga.mil/GandG/wgs84/ gravitymod/egm2008. (Ziyaret tarihi: 11 Şubat 2017).

Schultze-Westrum, H. H., 1961. Das Geologische Profil des Aksudere Tales bei Giresun-Ein Beitrag zur Geologie und Lagerstättenkunde der Ost-Pontischen Erz- und Mineralprovinz, NEAnatolien, M.TA. Bulletin, 57, 65-74.

Spector, A., Grant, F. S., 1970. Statistical models for interpreting aeromagnetic data. Geophysics, 35, 293-302.

Türkiye Maden Tetkik ve Arama Genel Müdürlüğü, http://www.mta.gov.tr/v3.0/bolgeler/trabzon, (ziyaret tarihi: 10 Şubat 2017). 
Araştırma Makalesi / Research Article

U.S. Geological Survey, Digital Elevation Models GTOPO30, Virginia, 1998, http://webmap.ornl. gov/wcsdown/wcsdown.jsp?dg_id=10003_1, (Ziyaret tarihi: 11 Şubat 2017).
Yılmaz, Y., 1984. Türkiye'nin jeolojik tarihinde magmatik etkinlik ve tektonik evrimle ilişkisi. Türkiye Jeoloji Bülteni, Ketin Sempozyumu, 6381. 